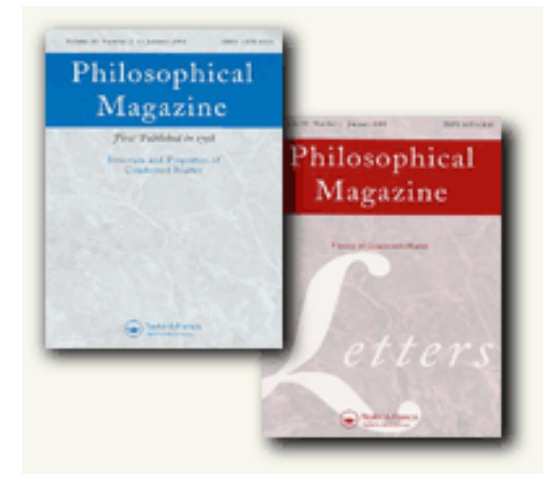

\title{
Surface energy of complex - and simple - metallic compounds as derived from friction test in vacuum
}

\begin{tabular}{|c|c|}
\hline Journal: & Philosophical Magazine \& Philosophical Magazine Letters \\
\hline Manuscript ID: & TPHM-05-May-0240.R1 \\
\hline Journal Selection: & Philosophical Magazine \\
\hline $\begin{array}{r}\text { Date Submitted by the } \\
\text { Author: }\end{array}$ & 26-Jun-2005 \\
\hline Complete List of Authors: & $\begin{array}{l}\text { Dubois, Jean-Marie; Ecole des Mines de Nancy, Laboratoire de } \\
\text { Science et Génie des Matériaux et de Métallurgie } \\
\text { de Weerd, Marie-Cécile; Ecole des Mines de Nancy, Laboratoire de } \\
\text { Science et Génie des Matériaux et de Métallurgie } \\
\text { Brenner, Josef; Austrian Centre of Competence for Tribology } \\
\text { Research GmbH } \\
\text { SALES, Muriel; Austrian Research Center Seibersdorf GmbH, } \\
\text { aerospace material technology } \\
\text { Mozdzen, Grazina; Austrian Research Centre-Seibersdorf Research } \\
\text { GmbH, aerospace material technology } \\
\text { merstallinger, Andreas; Austrian Research Centre-Seibersdorf } \\
\text { Research GmbH, aerospace material technology } \\
\text { Belin-Ferré, Esther; Laboratoire deChimie Physique Matiere et } \\
\text { Rayonnement UMR 7614 }\end{array}$ \\
\hline Keywords: & $\begin{array}{l}\text { X-ray spectroscopy, transition-metal compounds, surface tension, } \\
\text { ordered intermetallics, friction, electron energy states }\end{array}$ \\
\hline Keywords (user supplied): & \\
\hline
\end{tabular}

\section{(5) ScholarONE" \\ Manuscript Central}




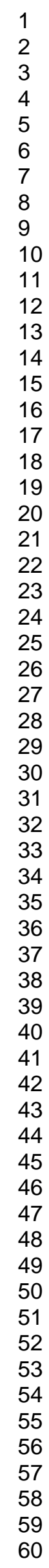

http://mc.manuscriptcentral.com/pm-pml 


\title{
Surface energy of complex - and simple - metallic compounds as derived from friction test in vacuum
}

\author{
J.-M. DUBOIS,,$^{+}$M.-C.de WEERD,${ }^{+}$J. BRENNER, ${ }^{\dagger}$ M. SALES, ${ }^{\ddagger}$ G. MOZDZEN, ${ }^{\ddagger}$ \\ A. MERSTALLINGER ${ }^{\ddagger}$ and E. BELIN-FERRÉ ${ }^{\times}$ \\ + Laboratoire de Science et Génie des Matériaux et de Métallurgie, Ecole des Mines, \\ Parc de Saurupt, F-54042 Nancy \\ ${ }^{\dagger}$ Austrian Centre of Competence for Tribology Research GmbH, Viktor-Kaplan Str. 2, \\ A-2700 Wiener Neustadt \\ ‡ Austrian Research Centre-Seibersdorf Research GmbH, A- 2444 Seibersdorf \\ ${ }^{x}$ Laboratoire de Chimie Physique Matière et Rayonnement, 11 rue P. et M. Curie, \\ F-75231 Paris Cedex 05
}

This article attempts to understand better the origin of low friction and zero solid-solid adhesion observed on quasicrystals placed in vacuum. We present an ensemble of experimental data that allows us on the one hand to estimate the true surface energy of unoxidized quasicrystals and approximants and on the other hand to point out a correlation with electronic densities of states.

Key Words: surface energy, friction, cold-welding, density of states, quasicrystals

* To whom correspondence should be addressed. Electronic mail: dubois@mines.inpl-nancy.fr 


\section{Introduction}

That Al-based quasicrystals exhibit low friction against hard materials like Cr-steel, diamond or alumina was first evidenced in 1992 using a standard scratch test procedure [1]. This test however leads to a rather weak contrast between sliding friction measured on multi-grain quasicrystals and materials of similar bulk mechanical properties such as the Vickers hardness $\mathrm{H}_{\mathrm{v}}$. This weak contrast is due to the tribo-oxidation of (essentially) aluminium, which obscures the friction of the bulk material underneath the oxide that forms upon sliding the indenter in ambient atmosphere and contributes to the growth of a third-body material left within the friction trace. In vacuum, the picture is much clearer as soon as the residual oxygen pressure in the atmosphere is kept below a threshold of approximately $10^{-6}$ mbar. It is then most often possible to adjust the velocity of the sliding pin relative to the substrate in such a way that a full mono-layer of oxide can not grow during the time elapsed between two successive passages of the indenter. The oxide is then removed by the contacting indenter and essentially unoxidized surfaces come into contact (except at the very beginning of the test).

A clear difference is observed in such conditions on the friction coefficient of hard steel riding on materials of very similar hardness (and as a matter of fact, bulk and shear moduli). A series of data is presented in Fig. 1 to illustrate this standpoint. Steel riding on itself produces a friction coefficient 3 to 4 times larger than on an icosahedral $\mathrm{Al}_{59} \mathrm{Cu}_{25.5} \mathrm{Fe}_{12.5} \mathrm{~B}_{3}$ sample of quite comparable hardness. Similarly, a fretting test in vacuum shows that the adhesion force measured between a spherical hard steel pin contacting a flat fcc $\mathrm{Cu}$ or Al substrate is about 100 times larger than the force measured in identical conditions against icosahedral samples [1].

The present article focuses at a presentation of more experimental data recorded in the same conditions, but for a variety of quasicrystals and approximants and for binary Altransition metal (TM) compounds. On this simple experimental basis, we point out a correlation between friction as deduced from our experiment on pure TM samples and their (known) surface energy, thus demonstrating that we indeed probe the actual surface energy of each compound. We then turn to cold welding and show how the adhesive force to various indenters is linked to partial densities of states in the studied intermetallic substrates.

\section{Experimentals}

\subsection{Samples}

A series of intermetallics based on aluminium was prepared from pure constituents using standard metallurgy techniques, followed by crushing into powder of selected granulometry (mesh size in the range 30 to $50 \mu \mathrm{m}$ ) and sintering into pellets of $20 \mathrm{~mm}$ in diameter and a few $\mathrm{mm}$ in thickness. After polishing in water down to mirror polish, drying in air and cleaning in an ultra-sound bath loaded with ethanol, these samples could be used for tribological testing. We also used Al-Pd-Mn single grains of the icosahedral phase and of the $\xi^{\prime}$-approximant of the decagonal phase that were kindly supplied to us by M. Feuerbacher from FZ-Juelich research centre.

\subsection{Experimental set-ups}

Two different experimental set-ups were used, respectively for friction and fretting data. The first one is a conventional pin-on-disk system, but housed in a vacuum chamber that 
may be evacuated down to $10^{-6} \mathrm{mbar}$ or less. At this later residual pressure, the fraction of oxygen still present in the chamber is sufficient to grow one single layer of alumina every second on pure fcc Al. The linear velocity of the disk with respect to the pin may be adjusted in such a way that the time elapsed between two successive passes of the indenter is comparable or smaller to the one necessary to grow a full mono-layer. In our experiment, we used the following parameters: linear velocity (pin vs disk) $=0.05 \mathrm{~m} / \mathrm{s}$; diameter of trace $=10-1210^{-3} \mathrm{~m}$; load $=2 \mathrm{~N}$; base pressure $=10^{-6}$ mbar or less.

The indenter was always a fresh hard steel ball of $6 \mathrm{~mm}$ in diameter. After each experiment, the wear experienced by the indenter and the flat surface counterpart was examined by optical and scanning electron microscopy. In most cases, the wear was negligible and no third-body formed, as evidenced by the absence of particles spalling off the bottom of the track and the absence of debris in the trace. Counter-examples were found however, as we will discuss later in this article.

The second set-up we used comprises a fretting test mechanism, also housed in a vacuum chamber that can be evacuated to typically the same residual pressure as in the previous experiment. A fretting movement is applied to the indenter, parallel to the studied flat surface by a piezo-electric actuator. A typical run consists of $10 \mathrm{~s}$ of alternating movements of $30 \mu \mathrm{m}$ amplitude at a frequency of $200 \mathrm{~Hz}$. The load and curvature of the pin are taken in such a way as to probe all surfaces under identical contact pressure relative to the elastic yield of each sample. The force that opposes the opening of the gap between pin and sample is measured after each run. It is called the stick force in the following. The values reported hereafter are averages over several hundred runs.

More details about both experimental facilities may be found in a companion paper to the present article [2].

\section{Results}

\subsection{Calibration}

With the view that friction in vacuum can be related to the surface energy $\gamma_{S}$ of the clean specimen, we have first studied a number of reference samples of known hardness and surface energy. These samples were chosen among $\mathrm{Al}$, pure transition metals $(\mathrm{TM}=\mathrm{Ti}$, $\mathrm{V}, \mathrm{Cr}, \mathrm{Mn}, \mathrm{Fe}, \mathrm{Co}, \mathrm{Ni}, \mathrm{Cu}, \mathrm{Zr}, \mathrm{Ta}, \mathrm{Hf}, \mathrm{W}$ ) and window glass, hard and mild steels, sintered alumina. At the end of the pin-on-disk test, material from steel pin has been transferred to the alumina surface, which in turn changes the relevant surface energy from that of alumina to that of iron (to a $1^{\text {st }}$ order approximation, neglecting the effect of alloying elements on $\gamma_{\mathrm{s}}$ ) with no change of the substrate hardness.

Figure 2 shows the value of the friction coefficient $\mu$ for $3 d, 4 d$ and $5 d$ TM elements, arranged along the $x$-axis according to increasing number of $d+s$ electrons. In the same figure, the data is represented after correcting the value of $\mu$ from the ploughing contribution to friction that is assumed simply proportional to the inverse of the hardness $H_{v}$, i.e. $\mu^{\prime}=\mu-\alpha / H_{v}$ (the model is therefore not valid for soft metals like $\mathrm{Sn}$ or $\mathrm{Pb}$ ). A clear similarity is found with the variation of the surface energy obtained from ab-initio calculations [3] or from experiments [4]. This is not true however for the metals that have the highest surface energy, i.e. Co, $\mathrm{Hf}$ and W. For those metals, $\mu$ ' is found dramatically below the expected value, thus pointing out a severe limitation of the method, namely that unoxidized surfaces must come into contact. With high $\gamma_{s}$ values, as for $W$, one expects indeed that covering the surface with adsorbates at pressures in the range offered by the 
present instrument will occur with high stick coefficient, so that the surface is always lubricated. As a consequence, $\mu$ is artificially reduced. A simple test of the occurrence of such an artefact is achieved by introducing a minute amount of oxygen in the chamber while the pin is running. Unoxidized surfaces show an immediate drop of $\mu$, whereas lubricated ones show only a gradual decrease, when not an increase. We could assess that all metals and reference samples, except $\mathrm{Co}, \mathrm{W}$ and $\mathrm{Hf}$, behave as clean surfaces in our experiments.

Accordingly, we assume that friction of hard steel in vacuum is dominated by an adhesion term towards the surface under study and contains also a ploughing contribution, so that we can write (except for too soft materials):

$$
\mu=\alpha / H_{v}+\beta W_{P S}
$$

where $\alpha$ and $\beta$ are fit parameters, and $W_{P S}$ stands for the adhesion energy between pin and solid. Considering that wear is un-important, as can be ascertained easily by microscopy inspection of the trace after the end of the test, we may replace $W_{P S}$ in Eq. (1) by the reversible adhesion energy between pin and disk. Eq. (1) reads then:

$$
\mu=\alpha / H_{v}+\beta\left(\gamma_{S}+\gamma_{P}-\gamma_{S P}\right)
$$

where $\gamma_{P}$ stands for the surface energy of the steel-made pin $\left(\approx 2.4 \mathrm{~J} / \mathrm{m}^{2}\right)$ and $\gamma_{S P}$ for the interfacial energy of the pin on the solid surface.

Since this later term is unknown, a further assumption must be made. Noticing that $\gamma_{S P}$ cannot be very different from the immersion energy of steel on a solid surface, we take the difference $\gamma_{P}-\gamma_{S P}$ as zero:

$$
\mu=\alpha / H_{v}+\beta \gamma_{S}
$$

When doing so, we exaggerate the result on $\gamma_{s}$ or in other words, we give an estimation of the upper limit of $\gamma_{S}$ for the various materials (which at the present time, is better that no value at all). Notice however in the following that the error on $\gamma_{S}$ can be a few tens of a percent.

A single set of $\alpha$ and $\beta$ parameters may be adjusted (Fig. 3) in order to match calculated values of the friction coefficient to experimental ones $(\alpha=34 \pm 0.5 ; \beta=0.322 \pm 0.005$, linear regression coefficient $r=0.96$ ). Inverting Eq. (3), and within the limits of the assumptions made above, this in turn may be used to decipher a correct estimate of the true surface energy of samples of suitable hardness (above about 100 Vickers units) and surface energy (below typically $2-2.5 \mathrm{~J} / \mathrm{m}^{2}$ ).

\subsection{Friction in vacuum}

The data collected so far are assembled in Table 1. We produce no data for $\mathrm{Al}_{13} \mathrm{Co}_{4}$ and Al-Ni compounds because the wear visible on our samples at the end of the tests was making application of this method invalid. Interestingly enough, values of $\gamma_{s}$ are found very much below the surface energy of the individual constituents for all icosahedral compounds, but also for superstructures of the $\beta$-phase in the Al-Cu system.

\subsection{Fretting test}

The tendency to cold-welding, as measured by the stick force, exhibited by icosahedral or high-order approximants is small, but depends on the nature of the counterpart. Whereas the stick force is sometimes found below the instrumental resolution when probed against hard steels, it is found significantly large against Al-based and Ti-based alloys [2], but nonetheless far less than the one measured with steel against fcc $\mathrm{Cu}$ and fcc Al [1]. A summary of our findings for a superstructure compound of the B2-Al-Cu phase, the icosahedral Al-Cu-Fe and Al-Pd-Mn compounds, the $\xi^{\prime}-\mathrm{Al}-\mathrm{Pd}-\mathrm{Mn}$ and orthorhombic O1-Al- 
$\mathrm{Cr}-\mathrm{Fe}(-\mathrm{Mo})$ approximants of the decagonal phase is given in Fig. 4. We discuss the data in the next section.

\section{Discussion}

That the stick force depends on the nature of the metallic counterpart (here essentially $\mathrm{Al}$ or $\mathrm{Fe}$ ) strongly suggests that it results from the formation of a band between electronic states in the sample and pin. In a very crude assumption, we shall assume it proportional to the number of $\mathrm{sp}$, respectively $\mathrm{d}$, states that merge with the Al, respectively Fe, states at the Fermi level $\left(E_{F}\right)$ present in the Al-based and steel pins, respectively. The number of $s, p$ and $d$ states at $E_{F}$ in our samples is obtained for the very same specimens by X-ray emission spectroscopy as explained elsewhere [5]. The result of this simple computation is shown in Fig. 4b. Although not perfect, the matching with the experimental data given in Fig. 4a is good enough to support our assumption.

In an attempt to rationalise our estimate of the surface energy, we plot it in Fig. 5a against the number of TM s+d electrons, using the same x-axis coordinate as in Fig. 2a. Again, two clear maxima are found at 5 and 9 e/at, respectively, and a minimum at 7 e-/at. However, the data for the icosahedral phases falls significantly below the values of $\gamma_{S}$ measured for the crystalline compounds (including compounds of nearby composition, which rules out the occurrence of an artefact like the one encountered with Co or W). The difference with respect to crystal compounds must therefore be intrinsic to the quasicrystalline structure and may be related to the formation of critical states that cannot be accounted for using the present free-electron picture. A similar trend is observed (Fig. $5 b)$ if one plots $\gamma_{s}$ as a function of the total number of $(\mathrm{sp}+\mathrm{d})$ electrons per atom in the AlTM alloy. Again, icosahedral compounds exhibit a smaller value of $\gamma_{S}$ compared to crystals of closely related total electron density. As expected, the overall trend observed on the figure is nevertheless a decrease of $\gamma_{s}$ with the filling of the hybrid sp- $d$ band.

Altogether, it appears from our data that both friction and fretting in vacuum are dominated by electronic effects in our samples, and that the influence of mechanical deformation is rather limited, when not negligible.

\section{Conclusion}

To the best of our knowledge, the present approach is the first that delivers a systematic assessment of the genuine surface energy for a whole family of Al-based compounds. Although it relies on rather crude approximations, the data for $\gamma_{s}$ are valuable i) because no other method is able to probe so many different compounds in an economic way, and ii) because the values of $\gamma_{s}$ so-obtained are upper limits for the actual surface energy. We found that quasicrystals of high lattice perfection exhibit a surface energy that is smaller than that of the pure constituents by a factor 2 to 3 , and falls in the range $0.5-0.8 \mathrm{~J} / \mathrm{m} 2$. Conversely, compounds with a pronounced metallic character show values of $\gamma_{s}$ that are not very different from that of the constituent metals. Epitaxy of metallic films on clean quasicrystal surfaces manifests growth morphologies that are consistent with this data [6].

\section{Acknowledgements}

The present work was supported by 'ERT Quasicristaux Industriels ' from French Ministry of Research and Technology and by Growth 2000 project 'Smart Quasicrystals' of the European Union under contract $n^{\circ}$ G5RD-CT-2001-00584. We are grateful to $M$. Feuerbacher, Juelich, for providing single domain specimens. 


\section{References}

[1] Dubois J.M., Useful Quasicrystals (World Scientific, Singapore, 2005) and references therein.

[2] Sales M. et al., this conference proceedings.

[3] Vitos, L., Ruban, A.V., Skriver, H.L., Kollar, J., Surface Science 411, 186-202 (1998)

[4] Eustatopoulos, N., Nicholas, M.-G., Drevet, B., Wettability at High Temperatures, (Elsevier, Amsterdam, 1999).

[5] Belin-Ferré E., Demange V., Dubois J.M., Crystallography Reviews 10, 111-179 (2004).

[6] Fournée V., this conference proceedings.

\section{Figure captions}

Fig. 1: Friction coefficient measured against hard steel in vacuum (a) and against diamond in air (b) for a variety of samples. The data is presented versus the materials hardness. Friction is always found smaller on a quasicrystal of good lattice perfection.

Fig. 2: Variation with the number of $\mathrm{TM} s+d$ electrons of the surface energy (from literature) (a) and friction coefficient $\mu$ ' corrected for the ploughing contribution (b). The same trends are observed on both figures for the $3 d$ series (solid squares), with marked maxima at 5 and 9 electrons and a minimum at 7, except for Co that is found very much below the expected value of $\mu^{\prime}$. A similarity between (a) and (b) figures is also observed for the $4 \mathrm{~d}$ (grey diamond) and $5 \mathrm{~d}$ (open triangles) TM series, except $\mathrm{W}$ that shows a too small value of $\mu$ '. For completeness of the figure, aluminium is indicated as well by a cross symbol (hence, the label $s p+d$ on the $x$-axis).

Fig. 3: Correlation between experimental values of the friction coefficient and values calculated according to Eq. (3). Hardness was measured, using a standard Vickers set-up and $\gamma_{s}$ data are from literature [3,4]. Small solid and open squares represent TMs, large squares are for alumina (bare: grey; open: covered with a Fe film) and window glass; the cross is for fcc Al.

Fig. 4: (a) Experimental stick force (in $\mathrm{mN}$ ) measured in vacuum on five compounds as labelled along the vertical axis and against spherical indenters: Al-based alloy (dark grey) and Fe-based steel (light grey). (b) Stick force (in arbitrary units), calculated assuming it is proportional to the number of electrons necessary to form a $\mathrm{sp}$ band with the Al-based indenter (dark grey) or a d band with the Fe-based indenter (light grey).

Fig. 5: Estimated surface energy $\gamma_{s}$ versus number of $s+d$ electrons of the TM constitutive species (a). The same $\gamma_{S}$ data is plotted in (b) against the total number of $s, p$ and $d$ electrons per atom in the compound. The open square is for icosahedral $\mathrm{Al}-\mathrm{Pd}-\mathrm{Mn}$ and the diamond for $\mathrm{i}-\mathrm{Al}-\mathrm{Cu}-\mathrm{Fe}$. 

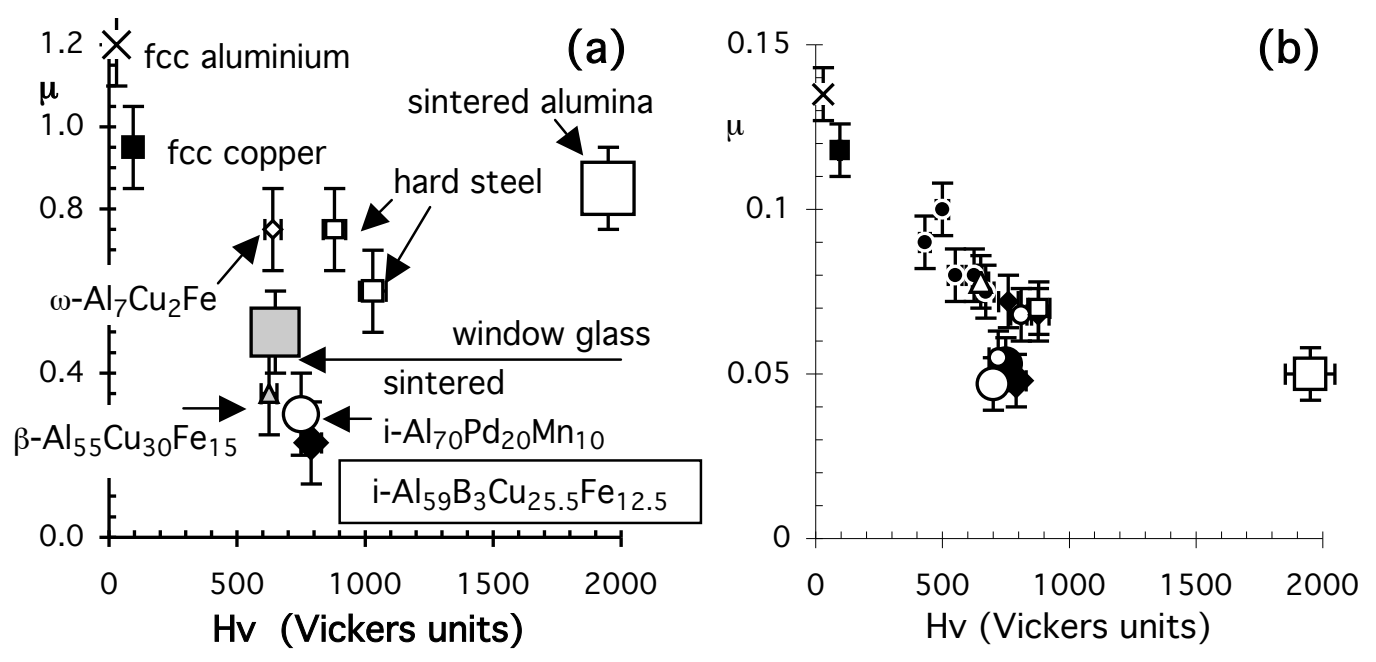

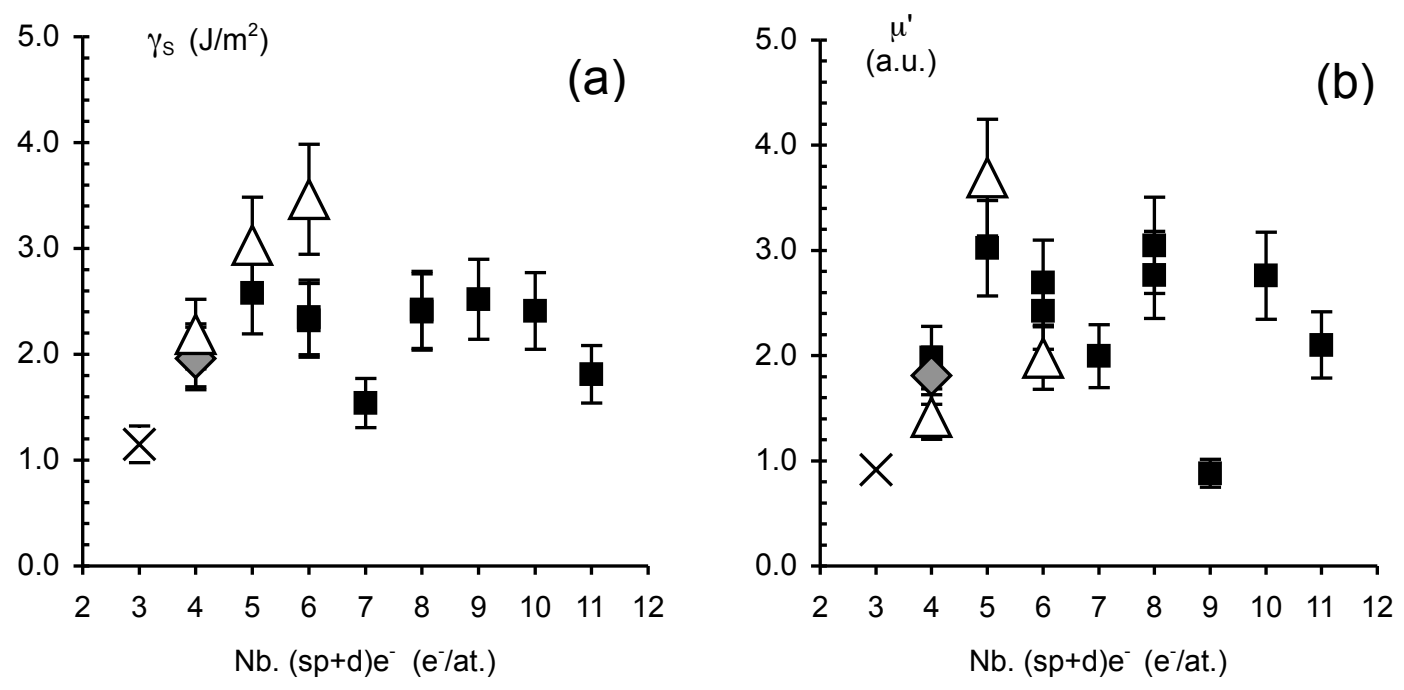


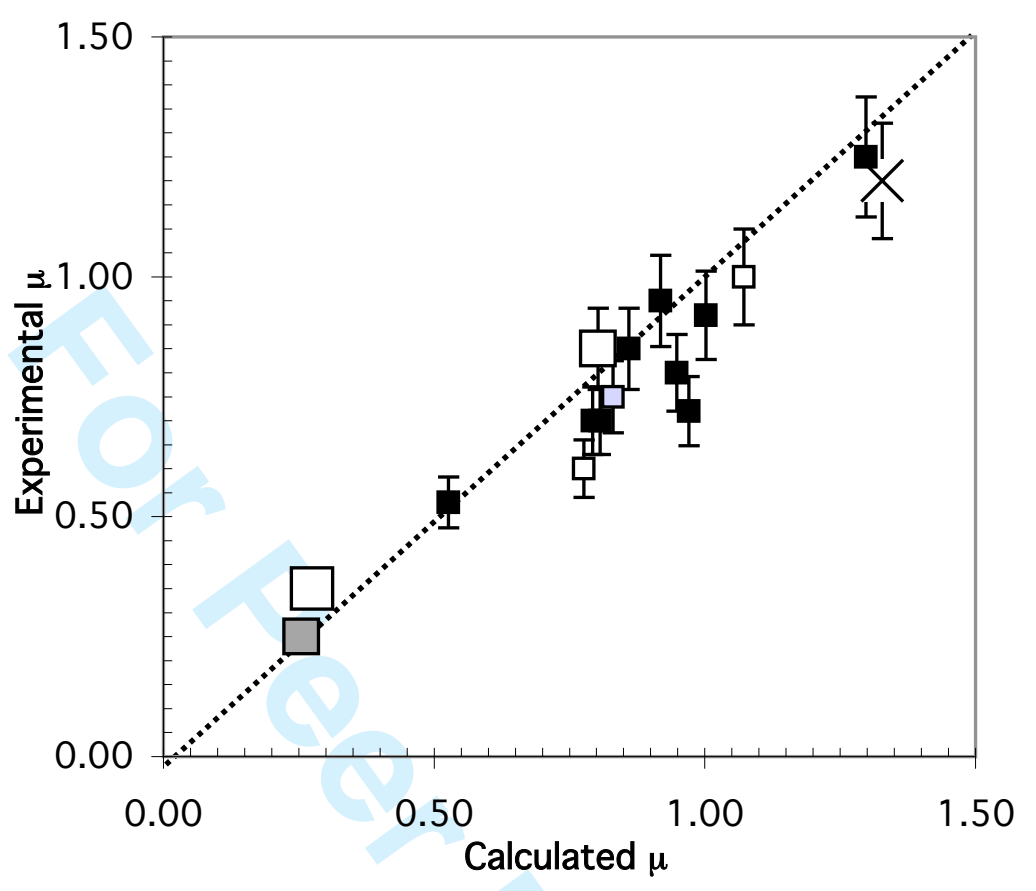



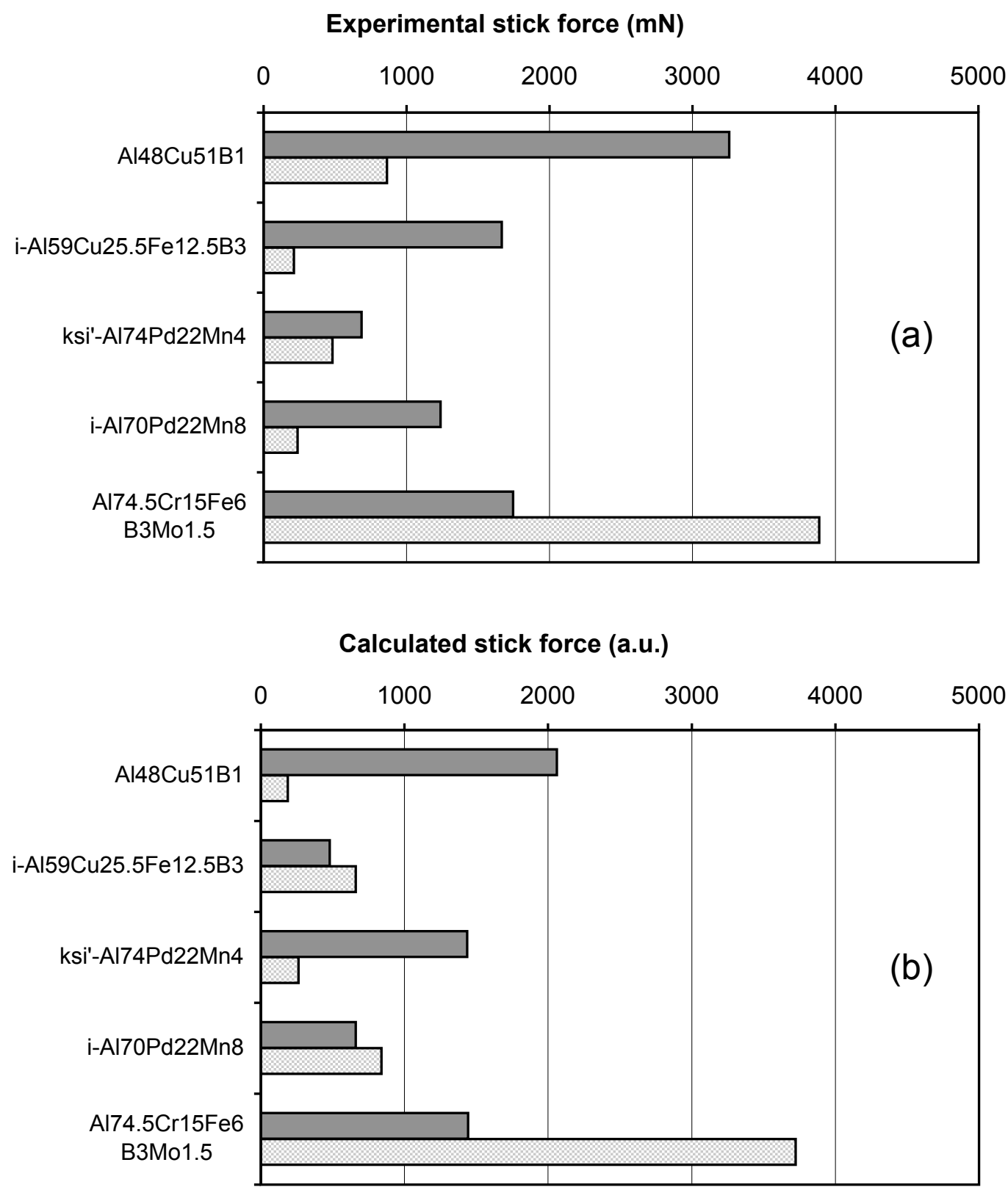

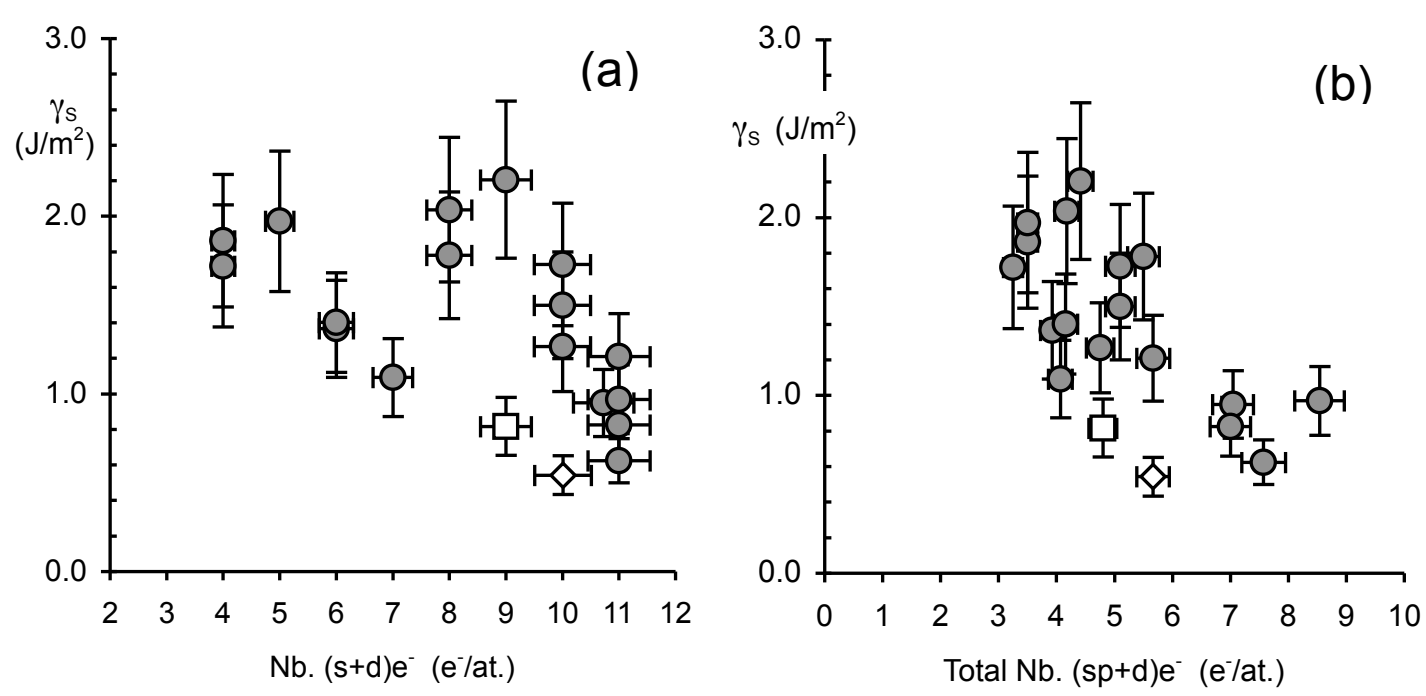
Table 1: Experimental results and estimated values of $\gamma_{\mathrm{s}}$.

\begin{tabular}{|c|c|c|c|c|}
\hline $\begin{array}{c}\text { Compound } \\
\text { (at.\% or atoms) }\end{array}$ & $\begin{array}{l}\text { Crystal } \\
\text { structure }\end{array}$ & $\begin{array}{c}\text { Vickers } \\
\text { Hardness } \\
\text { (load } 0.5 \mathrm{~N}) \\
\pm 8 \%\end{array}$ & $\begin{array}{c}\text { Friction } \\
\text { coefficient } \\
\pm 15 \%\end{array}$ & $\begin{array}{c}\text { Estimated } \\
\gamma_{S}\left(\mathrm{~J} / \mathrm{m}^{2}\right) \\
\pm 25 \%\end{array}$ \\
\hline $\mathrm{Al}_{3} \mathrm{Ti}$ & tetragonal & 604 & 0.6 & 1.72 \\
\hline $\mathrm{AlTi}$ & B2-cubic & 277 & 0.7 & 1.86 \\
\hline $\mathrm{Al}_{3} \mathrm{~V}$ & tetragonal & 427 & 0.7 & 1.97 \\
\hline $\mathrm{Al}_{9} \mathrm{Cr}_{4}$ & $\gamma$-brass & 695 & 0.48 & 1.37 \\
\hline $\mathrm{Al}_{8} \mathrm{Cr}_{5}$ & $\gamma$-brass & 720 & 0.49 & 1.40 \\
\hline $\mathrm{Al}_{11} \mathrm{Mn}_{4}$ & monoclinic & 476 & 0.41 & 1.09 \\
\hline$\lambda-\mathrm{Al}_{13} \mathrm{Fe}_{4}$ & monoclinic & 815 & 0.69 & $2.0_{4}$ \\
\hline 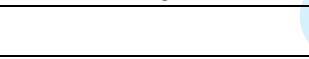 & B2-cubic & 417 & 0.64 & 1.78 \\
\hline $\mathrm{Al}_{3} \mathrm{Ni}$ & orthorhombic & 662 & 0.45 & 1.27 \\
\hline $\mathrm{Al}_{2} \mathrm{Cu}$ & tetragonal & 550 & 0.44 & 1.21 \\
\hline$\gamma-\mathrm{Al}_{9} \mathrm{Cu}_{4}$ & cubic & 480 & 0.37 & 1.0 \\
\hline $\mathrm{AlCu}$ & hexagonal & 806 & 0.3 & 0.82 \\
\hline oF-Al ${ }_{3} \mathrm{Cu}_{4}$ & orthorhombic & 710 & 0.24 & $0.6_{2}$ \\
\hline$\phi-\mathrm{Al}_{10} \mathrm{Cu}_{10} \mathrm{Fe}$ & cubic & 650 & 0.32 & 0.9 \\
\hline$\beta-\mathrm{Al}_{55} \mathrm{Cu}_{30} \mathrm{Fe}_{15}$ & B2-cubic & 680 & 0.31 & $0.8_{4}$ \\
\hline$\omega-\mathrm{Al}_{70} \mathrm{Cu}_{20} \mathrm{Fe}_{10}$ & tetragonal & 640 & 0.75 & 2.2 \\
\hline $\mathrm{Al}_{62} \mathrm{Cu}_{25.5} \mathrm{Fe}_{12.5}$ & icosahedral & 780 & 0.26 & $0.5_{5}$ \\
\hline $\mathrm{Al}_{59} \mathrm{~B}_{3} \mathrm{Cu}_{25.5} \mathrm{Fe}_{12.5}$ & icosahedral & 790 & 0.21 & $0.5_{4}$ \\
\hline $\mathrm{Al}_{70} \mathrm{Pd}_{20} \mathrm{Mn}_{10}$ & icosahedral & 750 & 0.3 & $0.8_{2}$ \\
\hline
\end{tabular}

